\title{
Chapter 3 \\ Determining Greenhouse Gas Emissions and Removals Associated with Land-Use and Land-Cover Change
}

\author{
Sean P. Kearney and Sean M. Smukler
}

\begin{abstract}
This chapter reviews methods and considerations for quantifying greenhouse gas (GHG) emissions and removals associated with changes in land-use and land-cover (LULC) in the context of smallholder agriculture. LULC change contributes a sizeable portion of global anthropogenic GHG emissions, accounting for $12.5 \%$ of carbon emissions from 1990 to 2010 (Biogeosciences 9:5125-5142, 2012). Yet quantifying emissions from LULC change remains one of the most uncertain components in carbon budgeting, particularly in landscapes dominated by smallholder agriculture (Mitig Adapt Strateg Glob Chang 12:1001-1026, 2007; Biogeosciences 9:5125-5142, 2012; Glob Chang Biol 18:2089-2101, 2012). Current LULC monitoring methodologies are not well-suited for the size of land holdings and the rapid transformations from one land-use to another typically found in smallholder landscapes. In this chapter we propose a suite of methods for estimating the net changes in GHG emissions that specifically address the conditions of smallholder agriculture. We present methods encompassing a range of resource requirements and accuracy, and the trade-offs between cost and accuracy are specifically discussed. The chapter begins with an introduction to existing protocols, standards, and international reporting guidelines and how they relate to quantifying, analyzing, and reporting GHG emissions and removals from LULC change. We introduce general considerations and methodologies specific to smallholder agricultural landscapes for generating activity data, linking it with GHG emission factors and assessing uncertainty. We then provide methodological options, additional considerations, and minimum datasets required to meet the varying levels of reporting accuracy, ranging from low-cost high-uncertainty to high-cost low-uncertainty approaches. Technical step-by-step details for suggested approaches can be found in the associated website.
\end{abstract}

\footnotetext{
S.P. Kearney • S.M. Smukler $(\bowtie)$

University of British Colombia, Vancouver, BC, Canada

e-mail: sean.smukler@ubc.ca
} 


\subsection{Introduction}

Land-use and land-cover (LULC) change contributes a sizeable portion of global anthropogenic GHG emissions, accounting for an estimated $12.5 \%$ of carbon emissions from 1990 to 2010 (Houghton et al. 2012). Significant demographic and socioeconomic pressures are exerted on carbon storing land uses such as forests in the tropics yet distribution and rates of change (e.g., loss of forests and agricultural intensification) in tropical smallholder landscapes remain very uncertain (Achard et al. 2002). Much of this uncertainty stems from the substantial heterogeneity of LULC that exists, often at very fine spatial scales, in such landscapes. Even within LULC categories, significant heterogeneity in carbon stocks often occurs as a result of drivers specific to smallholder agriculture, such as fallow rotations, uneven canopy age distribution, and integrated crop-livestock systems (Maniatis and Mollicone 2010; Verburg et al. 2009). These factors result in the need for monitoring strategies different from those developed for more commonly monitored LULC transitions such as large-scale deforestation and urban expansion (Ellis 2004). Here we present general considerations and a suite of methods for estimating net changes in GHG emissions that specifically address the conditions of smallholder agriculture. In the process we illustrate the relative trade-offs between costs of analysis, precision, and accuracy.

There are four basic steps required to calculate GHG emissions/removals from LULC change:

- Determine change in LULC. Changes in the areal extent of LULC classes must be determined by comparing data collected from two or more points in time.

- Develop a baseline. Observed changes in carbon stocks must be compared against a "business as usual" scenario of what would have happened in the absence of project activities. This step is generally carried out by either developing a baseline scenario or through direct observation of a reference region.

- Calculate carbon stock changes. Carbon stocks associated with LULC classes must be quantified for each point in time or emission factors must be used to calculate carbon stock changes and associated GHG emissions or removals.

- Assess accuracy and calculate uncertainty. Accuracy of each step must be assessed in order to determine the uncertainty associated with final emission/removal estimates associated with LULC changes.

It is important to note that these steps are not necessarily chronological. For example a baseline scenario could be developed prior to LULC change detection. Accuracy assessments should be done concurrently with each phase of data collection and analysis.

In order to carry out the above steps, two basic types of data are required, defined by the Intergovernmental Panel on Climate Change (IPCC) as activity data and emission factors (IPCC 2006). Activity data refer to the areal extent of chosen LULC categories, subcategories, and strata and are generally presented in hectares. Emission factors refer to the data used to calculate carbon stocks associated with activity data and are usually presented as metric tons of carbon (or carbon dioxide equivalents) per hectare. Emission factors may not be required for all carbon pools when carbon 
stock densities are inventoried directly using field sampling and/or remote sensing techniques. The IPCC Guidelines (2006) also lay out three tiers of methods used to calculate GHG emissions and reductions, which increase not only in precision and accuracy but also in data requirements and complexity of analysis. Tier 1 requires country-specific activity data but uses IPCC default emission factors that can be found in the IPCC Emission Factor Database (IPCC n.d.) and analysis is generally simple and of low cost. Tier 2 uses similar methods to Tier 1 but requires the use of some region- or country-specific emission factors or carbon stock data for key carbon pools and LULC categories (more information on key pools can be found in Sect. 3.4.1). Tier 3 requires high-resolution activity data combined with highly disaggregated inventory data for carbon stocks collected at the national or local level and repeated over time.

Collection of data to generate emission factors or calculate carbon stock densities is covered elsewhere in this book. The focus of this chapter is on the generation of activity data and the various methods available to link emission factors and/or carbon stock densities with activity data for estimating total carbon stocks and GHG emissions/removals at the landscape-scale. The following sections provide an overview of the general activities for each of the four steps required to calculate GHG emissions/reductions from LULC change, with a focus on smallholder agriculture landscapes. Trade-offs between uncertainty and cost are addressed and a variety of references-including existing protocols, scientific research, and review papers-are cited. Summary tables are presented at the beginning of each section, with a complete table at the end of the chapter (Table 3.8).

\subsection{Determining Change in LULC}

The IPCC Guidelines (2006) outline three specific Approaches to monitoring activity data (described in detail below). The three Approaches refer to the representation of land area and will influence the ability to meet the three IPCC Tiers, which indicate the overall uncertainty of GHG emission/reduction estimates (Table 3.1). In general, progressing from Approach 1 to 3 increases the amount of information associated with activity data but requires greater resources. It should be noted that increasing the information contained within activity data does not guarantee a reduction in uncertainty. Accuracy will ultimately depend on the quality of data and implementation of the Approach as much as the Approach itself (IPCC 2006). However, progressing from Approach 1 to 3 provides the opportunity for reducing uncertainty and meeting higher Tier requirements.

Approach 1 uses data on total land-use area for each LULC class and stratum but without data on conversions between land uses. The result of Approach 1 is usually a table of land-use areas at specific points in time and data often come from aggregated household surveys or census data. Results are not spatially explicit, only allow for the calculation of net area changes and do not allow for analysis of GHG emissions/removals for land remaining within a LULC category or the exploration of 
Table 3.1 Summary of activities to determine change in LULC at various uncertainty levels

\begin{tabular}{|c|c|c|c|c|}
\hline Activity & $\begin{array}{l}\text { Higher } \\
\text { uncertainty }\end{array}$ & $\begin{array}{l}\text { Mid-range } \\
\text { uncertainty }\end{array}$ & Lower uncertainty & \begin{tabular}{|l} 
Key \\
references
\end{tabular} \\
\hline \multirow[t]{2}{*}{$\begin{array}{l}\text { Data } \\
\text { acquisition }\end{array}$} & \multirow{2}{*}{$\begin{array}{l}\text { Approach 1 or } \\
2 \text { with minimal } \\
\text { or no data } \\
\text { collection } \\
\text { (using existing } \\
\text { aggregated } \\
\text { datasets such } \\
\text { as census or } \\
\text { existing maps) }\end{array}$} & $\begin{array}{l}\text { Approach } 2 \text { with } \\
\text { disaggregated } \\
\text { datasets (existing or } \\
\text { developed) }\end{array}$ & $\begin{array}{l}\text { Approach } 3 \text { with } \\
\text { mid-resolution } \\
\text { imagery and } \\
\text { supplementary data }\end{array}$ & \multirow{2}{*}{$\begin{array}{l}\text { De Sy et al. } \\
\text { (2012); IPCC } \\
\text { (2006); } \\
\text { Ravindranath } \\
\text { and Ostwald } \\
\text { (2008) }\end{array}$} \\
\hline & & $\begin{array}{l}\text { Approach } 3 \text { with } \\
\text { coarse or mid- } \\
\text { resolution imagery }\end{array}$ & $\begin{array}{l}\text { Approach } 3 \text { with very } \\
\text { high-resolution } \\
\text { imagery }\end{array}$ & \\
\hline \multirow[t]{2}{*}{$\begin{array}{l}\text { LULC } \\
\text { classification }\end{array}$} & \multirow{2}{*}{$\begin{array}{l}\text { Broad LULC } \\
\text { categories } \\
\text { developed } \\
\text { through } \\
\text { subjective } \\
\text { (non- } \\
\text { empirical) } \\
\text { survey } \\
\text { methods; not } \\
\text { spatially } \\
\text { explicit }\end{array}$} & $\begin{array}{l}\text { Broad LULC } \\
\text { categories with } \\
\text { simple subclasses or } \\
\text { strata }\end{array}$ & $\begin{array}{l}\text { Empirically derived } \\
\text { LULC categories and } \\
\text { strata }\end{array}$ & \multirow{2}{*}{$\begin{array}{l}\text { GOFC-GOLD } \\
\text { (2014); IPCC } \\
(2006) ; \\
\text { Vinciková } \\
\text { et al. (2010) }\end{array}$} \\
\hline & & $\begin{array}{l}\text { Classified using } \\
\text { visual interpretation } \\
\text { or pixel-based } \\
\text { techniques with } \\
\text { limited or imagery- } \\
\text { based training data; } \\
\text { spatially explicit }\end{array}$ & $\begin{array}{l}\text { Supervised } \\
\text { classification using } \\
\text { pixel-based, } \\
\text { object-based or } \\
\text { machine learning } \\
\text { techniques with } \\
\text { field-derived training } \\
\text { data; spatially explicit }\end{array}$ & \\
\hline $\begin{array}{l}\text { LULC } \\
\text { change } \\
\text { detection }\end{array}$ & $\begin{array}{l}\text { Arithmetic } \\
\text { calculation of } \\
\text { change in total } \\
\text { land area for } \\
\text { each LULC } \\
\text { class using } \\
\text { data generated } \\
\text { by Approach } 1\end{array}$ & $\begin{array}{l}\text { Arithmetic } \\
\text { calculation of } \\
\text { change in total land } \\
\text { area for each LULC } \\
\text { class and transitions } \\
\text { between LULC } \\
\text { classes using data } \\
\text { generated by } \\
\text { Approach } 2 \text { or; } \\
\text { post-classification } \\
\text { comparison with } \\
\text { coarse or mid- } \\
\text { resolution imagery }\end{array}$ & $\begin{array}{l}\text { Spatially explicit } \\
\text { change detection } \\
\text { using post- } \\
\text { classification } \\
\text { comparison, image } \\
\text { comparison, } \\
\text { bitemporal } \\
\text { classification or other } \\
\text { GIS-based } \\
\text { approaches }\end{array}$ & $\begin{array}{l}\text { Huang and } \\
\text { Song (2012); } \\
\text { van Oort } \\
(2007)\end{array}$ \\
\hline
\end{tabular}

drivers of LULC change. Therefore Approach 1 may not be suitable for carbon crediting under mechanisms such as the Verified Carbon Standard (VCS) or Reducing Emissions from Deforestation and Forest Degradation (REDD+) (see GOFC-GOLD 2014).

Approach 2 builds on Approach 1 by including information on conversions from one LULC class to another, but the data remain spatially non-explicit. This provides the ability to assess changes both into and out of a given LULC class and track conversions between LULC classes. A key benefit of Approach 2 is that emission factors can be modified (if data are available) to reflect specific conversions from one LULC category to another. For example, forests with a long history of prior cultivation may store less carbon than undisturbed forests of the same age (e.g., Eaton and Lawrence 2009; Houghton et al. 2012). Such factors cannot be taken into 
account using Approach 1. The results of Approach 2 can be expressed as a land-use conversion matrix of the areal extent of initial and final LULC categories.

Approach 3 uses datasets that are spatially explicit and compiled through sampling and wall-to-wall mapping techniques. Remotely sensed data (e.g., imagery from aerial- or satellite-based sensors) are often used in combination with georeferenced sampling such as field or household surveys. Data are then analyzed using geographic information systems (GIS) and can be easily combined with other spatially explicit datasets to stratify LULC categories and emission factors. This can greatly improve the accuracy of emission/removal estimates, especially for large areas, and allows for statistical quantification of uncertainty. Approach 3 can be an efficient way to monitor large areas. However it may require greater human and financial resources, which could be cost-prohibitive for smaller projects, especially if the spatial resolution of freely available or low-cost imagery is too coarse to detect LULC changes. (See Sect. 3.2.2 for more information about remotely sensed data.)

\subsubsection{Setting Project Boundaries}

The extent, location, and objectives of monitoring will all influence the appropriate choice of methods for analyzing LULC change and associated GHG emissions and reductions. While activity data may or may not be spatially explicit, the extent (i.e., boundaries) of the area monitored must be explicitly and unambiguously defined and should remain the same for all reporting periods. Several factors should be considered when defining the extent of the monitoring area.

Baseline Development and Data Availability. The availability of existing data (e.g., historical and/or cloud-free satellite imagery, forest inventories, research studies, census data) can determine the area for which a justifiable baseline scenario can be developed and therefore the project extent may need to be adjusted accordingly (Sect. 3.3). In some cases, it might be useful to adhere to political divisions rather than geographic boundaries if socioeconomic data are available in political units that do not correspond with geographic boundaries such as a watershed or ecoregion. If a reference region is to be used, it is important to consider whether one of appropriate size and characteristics can be found to match the chosen inventory extent (Sect. 3.3.2). For example the reference region may need to be 2-20 times larger than the project area to meet some VCS methodologies (VCS Association 2010).

IPCC Tier Selection. The inventory area may need to be reduced in order to meet higher IPCC Tier levels. For example, if a spatially explicit inventory (Approach 3) meeting IPCC Tier 3 guidelines is desired, expensive high-resolution satellite imagery and intensive data collection may be required and resource constraints may lead to a smaller inventory area. Meeting a lower IPCC Tier requirement could allow for the use of freely available imagery and/or existing data that could enable monitoring of a larger area.

Stratification and Variability. Ideally, inventory data will be collected in such a way as to sufficiently capture the spatial variability of key stratification variables. Identification of such variables a priori may reveal that it is impractical or financially 
unfeasible to develop a sampling strategy that can sufficiently capture variation within the entire area and the extent of the monitoring area may need to be adjusted.

Policy Levers. It is important to consider which policy levers exist, at what scale they can be applied and which may be influenced by assessment results when determining monitoring boundaries. For example, if regulations affecting land-use are implemented solely along political boundaries, it may not make sense to draw project-monitoring extents around watershed boundaries that may encompass multiple political units with differing regulations or policy options.

\subsubsection{Data Acquisition}

Data to estimate areal LULC extents can be acquired through three general sources: existing datasets developed for other purposes, collection of new data through sampling and complete LULC inventories using remote sensing data (Table 3.1).

\section{Existing Data}

Existing datasets can come from national or international sources or from other projects or research activities. Data may be available in a variety of formats and collection dates, and at varying spatial and temporal scales and extents. Time should be taken to identify existing data sources in order to determine what data remain to be collected, at what temporal and spatial scales and to what degree project resources can accommodate these needs. Useful datasets can include historical LULC maps, climate data, biophysical data (e.g., soil or hydrological maps), census or household surveys and political boundaries or administrative units.

\section{Ground-Based Field Sampling Methods}

Ground-based methods are recommended when existing datasets are incomplete, out of date, or inaccurate and complete spatial coverage with remote sensing techniques is unfeasible or would not be accurate on its own (IPCC 2003, Sect. 2.4.2). Ground-based sampling can be expensive and time consuming and is generally more appropriate for smaller project areas or when used in a sampling framework over larger areas. Field sampling to help determine LULC areal extents can result in two types of geographic data: biophysical data and socioeconomic data. Biophysical data generally require objective physical measurement of various land attributes (e.g., parcel size, vegetative composition). Ideally these measurements are georeferenced using GPS in order to integrate them with remote sensing data and enable accurate follow-up measurements. Socioeconomic data can be collected using a variety of methods including interviews, surveys, census, questionnaires, and 


\section{Box 3.1 Random and Targeted Sampling Methods for Generating LULC Activity Data}

\section{Random Sampling}

Random sampling is generally done using systematic or stratified sampling methods. Systematic sampling spatially distributes sampling locations in a random but orderly way, for example using a grid. Stratified sampling selects sample sites based on any number of environmental, geographic, or socioeconomic variables to achieve sampling rates in proportion to the distribution of the chosen variables across the inventory extent. Stratified sampling methods (e.g., optimum allocation) can improve the accuracy and reduce costs of monitoring efforts (Maniatis and Mollicone 2010) and tools exist to determine the number of sample plots needed (UNFCCC/CCNUCC 2009). Ideally sample sites for determination of LULC can be co-located with sites for measuring carbon stocks and GHG emissions, although this may not always be practical or feasible.

\section{Targeted Sampling}

Targeted sampling refers to the non-random selection of specific sample regions based on determined criteria. A common example of targeted sampling is the use of low-cost or free-imagery to identify "hotspots" of active LULC change such as deforestation (Achard et al. 2002; De Sy et al. 2012). These hotspots, or a randomly selected subset within, can then be selected as sample units for more in-depth monitoring using higher-resolution imagery and/or comprehensive fieldwork. These data can then be used to train LULC classification algorithms and assess the accuracy of results obtained using medium or coarse resolution imagery. Regardless of the method chosen, sampling should be statistically sound and allow for the quantification of uncertainty.

participatory rural appraisals (e.g., semistructured interviews, transect walks, and other flexible approaches involving local communities; see Ravindranath and Ostwald 2008 for more information). Socioeconomic data may or may not be georeferenced, depending on the application.

Both biophysical and socioeconomic data acquired using the methods mentioned above can give a reasonable estimate of the proportions of LULC categories within the inventory area provided sample locations are selected using statistically rigorous methods to maintain consistency and minimize bias. These proportions can then be multiplied by the total land area to generate activity data. Sample locations can be chosen using random or targeted (non-random) methods (Box 3.1). Random methods allow for quantification of uncertainties and are therefore generally preferred, but targeted methods may be useful for measuring carbon stocks related to a specific event (e.g., a fire) or calibration of modelling for a specific carbon pool (e.g., effects of decomposition on soil carbon) (Maniatis and Mollicone 2010). 


\section{Remote Sensing Data}

Complete wall-to-wall LULC inventories are generally carried out using a combination of remote sensing data and field-based sampling. Remotely sensed data come from aerial photography, satellite sensors, and airborne or satellite-based RADAR or LiDAR. Optical sensors are the most commonly used in LULC classification as they provide spectral information in the visible and infrared bands at a range of resolutions and costs (Table 3.2). While fine $(<5 \mathrm{~m})$ or medium $(10-60 \mathrm{~m})$ resolution imagery are preferable for accurately monitoring LULC in landscapes dominated by smallholder agriculture, cost of acquisition and/or processing may be prohibitive for projects covering large areas. However, methods exist for nesting high-resolution sampling within coarser resolution wall-to-wall coverage to reduce uncertainty of LULC change analysis across large areas and lower costs (e.g., Achard et al. 2002; Jain et al. 2013).

Image processing techniques can be applied to the remotely sensed data to enhance particular land-cover types, or enable more accurate stratification and classification, such as the calculation of the Normalized Difference Vegetation Index (NDVI), developing textural variables (e.g., Castillo-Gonzalez 2009) or principle component analysis (PCA). Imagery can also be classified into land-cover classes enabling easier manipulation in a GIS. Spatial analysis of remotely sensed data combined with environmental and/or socioeconomic variables can also create additional datasets to further enhance classification and stratification. Designating ecological or anthropogenic biomes (Ellis and Ramankutty 2008), calculating market accessibility (Chomitz and Gray 1996; Southworth et al. 2004) and identifying landscape mosaics (Messerli et al. 2009) are examples of such user-generated datasets to improve analysis of LULC change and explore drivers of change in smallholder landscapes.

\section{Spatial Considerations}

The spatial scale(s) at which data collection and analysis will take place is a key factor to consider when developing a monitoring and analysis program. Changing the scale at which analysis takes place can result in significantly different results, even when using the same dataset. The "optimal" scale of measurement and prediction is project-specific and may even vary for different steps of analysis (Lesschen et al. 2005). Complementary analysis at multiple scales may further improve accuracy (Messerli et al. 2009). A number of factors related to spatial scale should be considered to maintain transparency, and improve accuracy and efficiency of analysis.

The finest-scale unit of data is called a minimum information unit or minimum mapping unit (MIU or MMU). This is often the size of a small contiguous group of pixels for remote sensing data or the household for census data, although data may only be available aggregated to an administrative unit such as a village or municipality. To qualify for carbon credits, for example under the REDD+ mechanism, MMUs of <1-6 ha are generally required (De Sy et al. 2012; GOFC-GOLD 2014). In land- 


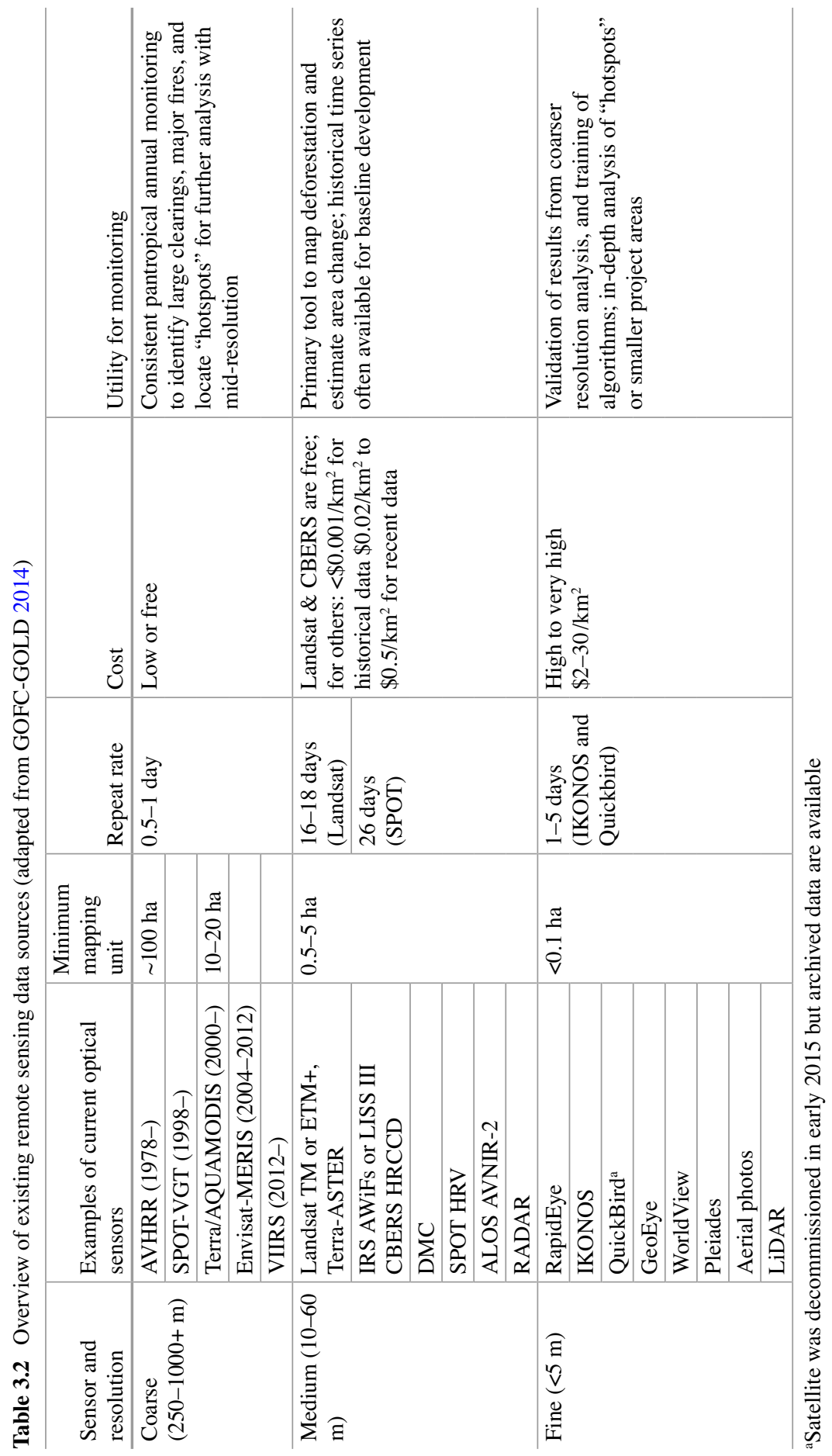


scapes dominated by smallholder agriculture, individual LULC parcels are often 0.5 ha or smaller. When using remote sensing data, it is preferable to have MIUs (e.g., pixels) that are significantly smaller than the average farm size to avoid mixed pixels that encompass multiple LULC categories. However methods of remote sensing analysis, such as spectral unmixing (Quintano et al. 2012) and hierarchical training with very high-resolution imagery (e.g., Jain et al. 2013) have been developed to attempt to deal with the issue of mixed pixels in coarser resolution imagery.

It is important to consider the scale of all available data to avoid mismatches that could lead to data management problems or wasted resources. Depending on the analysis methods used, data may have to be resampled to the coarsest available dataset. For example, it may be unnecessary to acquire a $5 \mathrm{~m}$ digital elevation model for stratification if it will be combined with $30 \mathrm{~m}$ Landsat data.

\section{Temporal Considerations}

Several temporal boundaries should be fixed established during the development of a monitoring methodology.

Historical reference period. If developing a baseline scenario from a historical reference period, this period must be specifically defined and appropriate for scenario development.

Monitoring period: The period for which changes in GHG emissions and reductions from LULC change are to be monitored.

Timing of monitoring: The schedule for monitoring to take place. Care should be taken to acquire imagery and/or carry out field sampling as close to the same time of year as possible for each monitoring period as interannual variability in vegetative cover and phenology may vary significantly in some locations (Huang and Song 2012; Serneels et al. 2001). Changes in carbon stocks from LULC change, such as declines in soil organic carbon (SOC) or vegetative regrowth, may not be linear within a monitoring period or may level off to zero-change within the period, also requiring appropriately timed sampling or modelling.

Monitoring frequency: The frequency of monitoring activities (e.g., imagery acquisition, field-sampling, surveys). Management strategies within a LULC category, for example cropping intensity, can have significant impacts on carbon stocks (e.g., Schmook 2010). More frequently, strategically timed data collection (i.e., sampling and/or image acquisition) is often required to detect changes in management strategies within an LULC category (De Sy et al. 2012; Jain et al. 2013; Smith et al. 2012). In most cases, particularly when dealing with remote sensing, increasing the temporal resolution of data (i.e., more frequent acquisition) necessitates declining spatial coverage and resolution (due to either technological or cost-prohibitive factors) and this trade-off must be considered when choosing between data sources.

LULC change definitions. The time period after which a change in LULC is considered permanent must be determined. For example, shifting cultivation, common practice in smallholder agriculture, results in cycles of cultivation and fallow periods that vary year to year, yet can resemble managed or secondary forest- 
cover when observed over the long term (Houghton et al. 2012). These temporary changes in land-cover (e.g., from annual cropping to secondary forests) can be misinterpreted as afforestation or deforestation depending on the timing of sampling or image acquisition if they are not considered across their entire cycle with sufficiently frequent measurements (DeFries et al. 2007). One approach to account for fluctuating carbon stocks associated with shifting cultivation is to calculate time-averaged carbon stocks for a given land-use system (Bruun et al. 2009; Palm et al. 2005).

Other considerations. Many studies have found that land-use is often influenced by land features. For example, farmers may choose to cultivate areas with fertile, carbon-rich soils (e.g., Aumtong et al. 2009; Ellis and Ramankutty 2008; Jiao et al. 2010) or reduce fallow periods when the soil fertility is high (Roder et al. 1995) and leave forests intact only in areas with poor soils. This preferential selection can make it difficult to determine that land-use is in fact causing a change in soil carbon stocks, and not the other way around (soil carbon stocks influencing land-use). Repeated sampling may be required to observe carbon stock changes resulting directly from LULC conversion (Bruun et al. 2009). The effects of prior land-use on future carbon sequestration potential may also be significant (see Eaton and Lawrence 2009; Hughes et al. 1999). While difficult to quantify, these delayed fluxes can be included when considering LULC transitions (e.g., a forest converted from agriculture may not store the same amount of carbon as a forest converted from a pasture). Finally, complications can arise from temporal mismatching, for example if biophysical or social data are collected in a separate time period from satellite imagery. There may be benefits from matching the timing of data acquisition on various factors (Rindfuss et al. 2004).

\subsubsection{LULC Classification and Change Detection}

\section{LULC Category Definition}

Regardless of the Approach used to generate activity data, LULC categories must be clearly and objectively established and LULC categories, subcategories, and strata should be mutually exclusive and totally exhaustive (Congalton 1991) with clear definitions of transitions from one class to another. (Note that sophisticated analysis methods using non-discrete, probabilistic or "fuzzy" classification do exist (e.g., Foody 1996; Southworth et al. 2004), but are beyond the scope of this chapter). For example, forests are generally defined based on a threshold value of minimum area, height and tree crown cover and the Designated National Authority (DNA) for each country can aid in defining LULC category definitions (GOFC-GOLD 2014). Objective definitions are especially important in smallholder landscapes where shifting cultivation and fallow rotations are common and transitions between LULC classes may not be straightforward. Furthermore, since smallholder landscapes often consist of small and heterogeneous land uses, it is possible that sampling points may 
fall into more than one LULC category. Systematic, transparent, and objective methods are needed to determine to which LULC category a sampling point belongs (Maniatis and Mollicone 2010).

The IPCC Agriculture, Forestry, and Other Land-Use (AFOLU) Guidelines (2006) define the following six broad land-use categories:

- Forest Land

- Cropland

- Grassland

- Wetlands

- Settlements

- Other Land

These top-level classes were designed to be broad enough to encompass all land areas in a country and allow for consistent and comparable reporting between countries. Monitoring activities can further divide these classes into conversion categories (i.e., Forest Land converted into Cropland, Wetlands converted into Settlements). For REDD+ GHG inventories and Tiers 2 and 3 reporting, it is likely that these top-level classes must be further divided into subcategories and/or stratified to allow for disaggregation of carbon stocks and improved estimation accuracy. Subcategories refer to unique LULCs within a category (e.g., secondary forest, within Forest Land) that impact emissions and for which data are available. Identification of subcategories can greatly reduce uncertainty of carbon stock estimates. For example, Asner et al. (2010) found that secondary forests held on average $60-70 \%$ less carbon than intact forests in the Peruvian Amazon, and other studies have found similarly large differences in carbon stocks between forest types (e.g., Eaton and Lawrence 2009; Saatchi et al. 2007), highlighting the importance of forest subclasses. Secondary forests, a significant LULC class in smallholder landscapes, are estimated to make up more than half of tropical forested areas and can be an important source or sink of carbon (Eaton and Lawrence 2009; Houghton et al. 2012). Therefore, distinguishing between secondary forests, bush-fallows, and undisturbed forests, while often challenging, will likely result in more accurate carbon stock estimates.

Stratification within LULC categories and subcategories can be based on any number of factors significant to emission estimation such as climate, ecological zone, elevation, soil type, and census data (e.g., population, management practices) (see Stratification, below). Final LULC categories and strata will depend on project location, climate and ecological factors, data availability, analysis capacity, and other factors. Ideally, however, subcategories or strata can be aggregated to correspond with the six broad land-use categories listed above to maintain consistency between country or project inventories. Designation of LULC classes and strata will also depend on the IPCC Approach chosen to represent land-use area data. To meet Approaches 2 and 3, data on conversion between LULC categories and strata must be available, potentially limiting the number of possible subcategories and strata. 


\section{LULC Classification, Mapping, and Tabulation}

Non-spatially explicit methods for collecting activity data (Approaches 1 and 2) result in tables of land area totals by LULC category for a given point in time. Depending on how data are collected, these results can be aggregated to political or geographic boundaries and incorporated into existing maps. The data themselves are not spatially explicit in their disaggregated form and therefore exact patterns of land-use cannot be interpreted within the spatial unit of aggregation (Table 3.1). The original data will generally come from LULC surveys, census data, existing maps or a combination of these. Therefore uncertainty associated with Approaches 1 and 2 will depend in large part on the quality of the sampling methods used to collect the original data. Costs could range greatly depending on the size of the project area, availability of existing data, heterogeneity of the landscape, and accessibility, but in general Approaches 1 and 2 can be low-cost options, especially for smaller projects.

Spatially explicit methods for generating activity data (Approach 3) use a combination of remote sensing and field-based sampling to develop a wall-to-wall classified LULC map with which LULC category areas can be totalled. Wall-to-wall maps provide the opportunity for interpolation between data points using GIS software and the development of spatially explicit polygons and/or individual pixels assigned to various LULC categories. In this manner activity data can be efficiently calculated, overlaid with ancillary data for stratification, and integrated with emission factors to quantify and analyze GHG emissions/reductions, their spatial variability, and drivers. Many methods exist to classify LULC, but they can be grouped into three main categories: visual interpretation, unsupervised classification, and supervised classification (Box 3.2). Additionally, a number of pre- and/or postprocessing steps may also be required to ensure accurate results. Choice of classification methods and image processing will depend on available resources, technical expertise, imagery, location, and available software. Greater detail on specific methodologies is presented on the associated website. Whichever methods are chosen for preprocessing, classification, and post-processing, they should be transparent, repeatable by different analysts, and results should be assessed for accuracy (GOFC-GOLD 2014).

\section{Stratification}

Once LULC classes have been identified and imagery classified, stratification by one or more variables may be desirable to improve estimation of carbon stocks, GHG emissions and reductions, and/or baseline development. The primary goal of stratification is to minimize the variability of carbon stock estimates within LULC categories (Maniatis and Mollicone 2010). The most basic form of carbon stock stratification is the development of subcategories (e.g., secondary forest versus mature forest; tree crops versus annual crops). Additional datasets and/or more intensive sampling may be required to identify subcategories, which may increase costs, 


\section{Box 3.2 General LULC Classification Methods Using Remote Sensing Data}

\section{Visual interpretation}

The simplest method of LULC classification is visual interpretation. In this method, a person familiar with the landscape and the appearance of LULC classes in remotely sensed imagery, manually interprets and classifies polygons around different land-covers. This method can be quite accurate but may not be precisely repeatable and can result in high uncertainty if comparisons are made between maps classified by different people. However systematic approaches to visual interpretation can increase accuracy and repeatability (e.g., Achard et al. 2002; Ellis 2004; Ellis et al. 2000).

\section{Unsupervised classification}

This method is fully automated and classification occurs without direct user intervention, although parameters such as the number of classes to be identified can be set by the user. Unsupervised classification algorithms cluster pixels into spectrally similar classes and very small spectral differences between classes can be identified (Vinciková et al. 2010). This method can be useful for exploring the number and distinguishability of potentially identifiable classes.

\section{Supervised classification}

Supervised classification relies on the training data that is used to calibrate automated or semiautomated classification algorithms. Training data may be obtained through field sampling, separate higher-resolution remote sensing imagery or from within the original image. Ideally training points will be chosen in a statistically rigorous way (e.g., random, stratified, systematic) and spatial and temporal factors should be considered (Sect. 3.2.2, Spatial Considerations and Temporal Considerations).

- Pixel-based supervised classification. Pixel-based supervised classification is one of the most commonly used classification methods. It uses spectral information for placing individual pixels into classes. Algorithms use training data and predetermined classes identified by the user to classify pixels. Statistical methods such as signature separability functions can be used to evaluate the quality of training of data and improve classification accuracy (Moreno and De Larriva 2012). One drawback to pixel-based classification, be it supervised or unsupervised, in smallholder agriculture landscapes is the problem of mixed pixels where individual pixels encompass multiple LULCs. Spectral mixture analysis (SMA), also called spectral unmixing, can overcome this problem by assigning individual pixels an estimated proportional value of multiple LULC classes (Quintano et al. 2012). SMA can improve classification accuracy in heterogeneous landscapes but requires significant technical expertise and expensive GIS software.

- Object-based classification. The primary goal of object-based classification is to identify MIUs on which to base classification criteria (Castillejo- 


\section{Box 3.2 (continued)}

González et al. 2009). In pixel-based classification, the pixel is the MIU whereas object-based methods quantitatively group pixels that are spectrally similar and spatially adjacent to create new MIUs representing patches or parcels of homogenous land-covers. Classification is then carried out on individual objects using a combination of spatial and spectral information. Object-based techniques combined with high-resolution imagery have not only been shown to outperform pixel-based methods in highly heterogeneous landscapes (e.g., Moreno and De Larriva 2012; Perea et al. 2009) but also require extensive technical expertise, time, and specialized GIS software.

- Other supervised classification techniques - Additional, relatively complex techniques such as regression/decision trees, neural networks, hierarchical temporal memory (HTM) networks (Moreno and De Larriva 2012), and support vector machines (Huang and Song 2012) have also shown success in improving classification accuracy in heterogeneous landscapes.

and transparent objective methods should still be used to define subcategories. However, stratification can reduce overall costs if monitoring activities can be targeted toward subcategories in which LULC transitions and carbon stock changes are expected (GOFC-GOLD 2014). Further stratification can be done using biophysical (e.g., slope, rainfall, soil type) and socioeconomic (e.g., population) datasets. Combining datasets requires either spatially explicit data (Approach 3) or datasets following Approaches 1 or 2 that have been aggregated to spatially defined units such as administrative boundaries. (See Lesschen et al. (2005) for a good overview on combining datasets for analysis of LULC change in farming systems.)

Stratification should only be carried out to the degree that chosen strata improve carbon stock estimates and reduce uncertainty. Statistical methods such as multivariate and sensitivity analyses exist to assess the quality of potential strata. Project objectives, timeframe, and the temporal and spatial resolution of available data will also impact the choice of LULC subcategories and strata.

\section{LULC Change Detection}

When using activity data generated with Approaches 1 and 2, change detection can be as simple as carrying out basic arithmetic to calculate the change in total land area of each LULC class at two or more points in time. Approach 2 will include results on the specific transitions observed (e.g., from forest to cropland versus from forest to pasture) and results are generally reported using a land-use conversion matrix (IPCC 2006; Ravindranath and Ostwald 2008).

Spatially explicit methods (Approach 3) to detect changes in LULC can be separated into three general categories: post-classification comparison, image 
comparison approach, and bitemporal classification approach. Post-classification comparison is the most straightforward approach and consists of first conducting separate LULC classifications on two or more images and comparing the results to detect change. Post-classification change detection is popular due to the fact that hard classification for single-date imagery is often required for other purposes or preexisting classified images are being used for one or more dates (van Oort 2007). One major drawback to this approach is that each image will contain uncertainty stemming from misclassification, which could result in significant errors in the change map from misidentification of LULC change. The image comparison approach attempts to reduce these errors by comparing the two unclassified images and identifying pixel-based change thresholds through methods such as differencing, ratioing, regression, change vector analysis, and principal component analysis (Huang and Song 2012). Bitemporal classification goes a step further by analyzing multiple images simultaneously and applying one of a variety of algorithms to produce a final map with change classes in a one-step process (Huang and Song 2012). The two latter approaches can be more adept at detecting specific changes of interest and more subtle changes (van Oort 2007) and may reduce uncertainty in cases where classification accuracy is low.

\subsection{Developing a Baseline}

Activity data are monitored at two or more points in time to assess LULC change. However, this change must be compared against a "business as usual" scenario to determine additionality (i.e., to define what would have occurred in the absence of project interventions). Only by comparing observed changes against a well-developed and justified baseline can we be sure that project activities resulted in changes that would not have occurred otherwise. Two general methods exist to develop a comparative baseline of LULC change: the development of a baseline scenario or the monitoring of a reference region.

\subsubsection{Baseline Scenarios}

A baseline scenario predicts the LULC changes that would occur within the inventory area in the absence of interventions by creating a "business as usual" scenario from a variety of input data (Table 3.3). This scenario can be developed on a project-by-project basis using conditions and information particular to the project (project-specific approach) or for a specific geographic area, which may extend beyond the project area boundaries (regional baseline approach, also called the performance standard approach). Either approach can be based on historical data and/or logical arguments about economic opportunities that could influence future LULC change (Sathaye and Andrasko 2007) and examples of both approaches are given in 
Table 3.3 Summary of activities for developing a baseline at various uncertainty levels

\begin{tabular}{|c|c|c|c|c|}
\hline Activity & $\begin{array}{l}\text { Higher } \\
\text { uncertainty }\end{array}$ & $\begin{array}{l}\text { Mid-range } \\
\text { uncertainty }\end{array}$ & Lower uncertainty & Key references \\
\hline \multirow[t]{2}{*}{$\begin{array}{l}\text { Baseline } \\
\text { scenario } \\
\text { development }\end{array}$} & \multirow[t]{2}{*}{$\begin{array}{l}\text { Logical } \\
\text { arguments or } \\
\text { simple trend } \\
\text { analysis based } \\
\text { on limited } \\
\text { historical data }\end{array}$} & \multirow{2}{*}{$\begin{array}{l}\text { Projection of } \\
\text { historical LULC } \\
\text { trends using } \\
\text { multitemporal } \\
\text { historical data } \\
\text { and/or simple } \\
\text { predictor } \\
\text { variables; or } \\
\text { monitoring of a } \\
\text { similar reference } \\
\text { region }\end{array}$} & $\begin{array}{l}\text { Modelled baseline } \\
\text { developed using } \\
\text { empirically derived } \\
\text { predictor variables } \\
\text { from multitemporal } \\
\text { historical datasets; or }\end{array}$ & \multirow[t]{2}{*}{$\begin{array}{l}\text { Brown et al. } \\
\text { (2007); } \\
\text { Greenhalgh } \\
\text { et al. (2006); } \\
\text { Sathaye and } \\
\text { Andrasko } \\
(2007)\end{array}$} \\
\hline & & & $\begin{array}{l}\text { Monitoring of a highly } \\
\text { similar reference } \\
\text { region with clearly } \\
\text { defined comparative } \\
\text { thresholds }\end{array}$ & \\
\hline $\begin{array}{l}\text { Baseline } \\
\text { justification }\end{array}$ & $\begin{array}{l}\text { Logical } \\
\text { arguments and/ } \\
\text { or qualitative } \\
\text { investment, } \\
\text { barrier or } \\
\text { common } \\
\text { practice } \\
\text { analysis }\end{array}$ & $\begin{array}{l}\text { Investment, barrier } \\
\text { and/or common } \\
\text { practice analysis } \\
\text { using limited } \\
\text { quantitative } \\
\text { analysis }\end{array}$ & $\begin{array}{l}\text { Development of } \\
\text { alternative baseline } \\
\text { scenarios with } \\
\text { investment and/or } \\
\text { barrier analysis and } \\
\text { common practice } \\
\text { analysis using } \\
\text { quantitative } \\
\text { approaches }\end{array}$ & $\begin{array}{l}\text { Greenhalgh } \\
\text { et al. (2006); } \\
\text { VCS } \\
\text { Association } \\
\text { (2012) }\end{array}$ \\
\hline
\end{tabular}

Table 3.4. The project-specific approach is often based on logical arguments where the baseline scenario is identified as the scenario facing the fewest barriers (Greenhalgh et al. 2006). This approach requires the development of multiple scenarios for the project area and requires economic-related data to evaluate which is most likely to occur. The regional baseline approach uses time-based estimates to project future carbon stock changes. This approach may require more GHG-related and spatially explicit data to enable quantitative analysis of trends in LULC change and GHG emissions/removals (Greenhalgh et al. 2006). The regional approach can result in more credible and transparent baselines and reduce costs when multiple projects are proposed within the same region (Brown et al. 2007; Sathaye and Andrasko 2007). An example of a potentially very useful dataset for identifying historical trends of forest-related disturbances is the high-resolution global forest change map recently published by Hansen et al. (2013).

Modelling future LULC changes based on historical and current data can be done using solely historical trends in percent change in land area or by incorporating drivers of LULC change into predictive models. Projection of historical LULC change trends requires reliable activity data for at least two points in time, preferably at the beginning and end of the historical period. Drivers used in modelled baselines can be simple metrics (e.g., population growth) to meet Tiers 1 and 2, or a more complex combination of spatially explicit biophysical and socioeconomic factors to meet Tiers 2 and 3. Drivers can greatly improve baseline development by capturing periodic fluctuations or variations across a landscape that may not be captured using trend analysis (Sathaye and Andrasko 2007). For example historical deforestation 


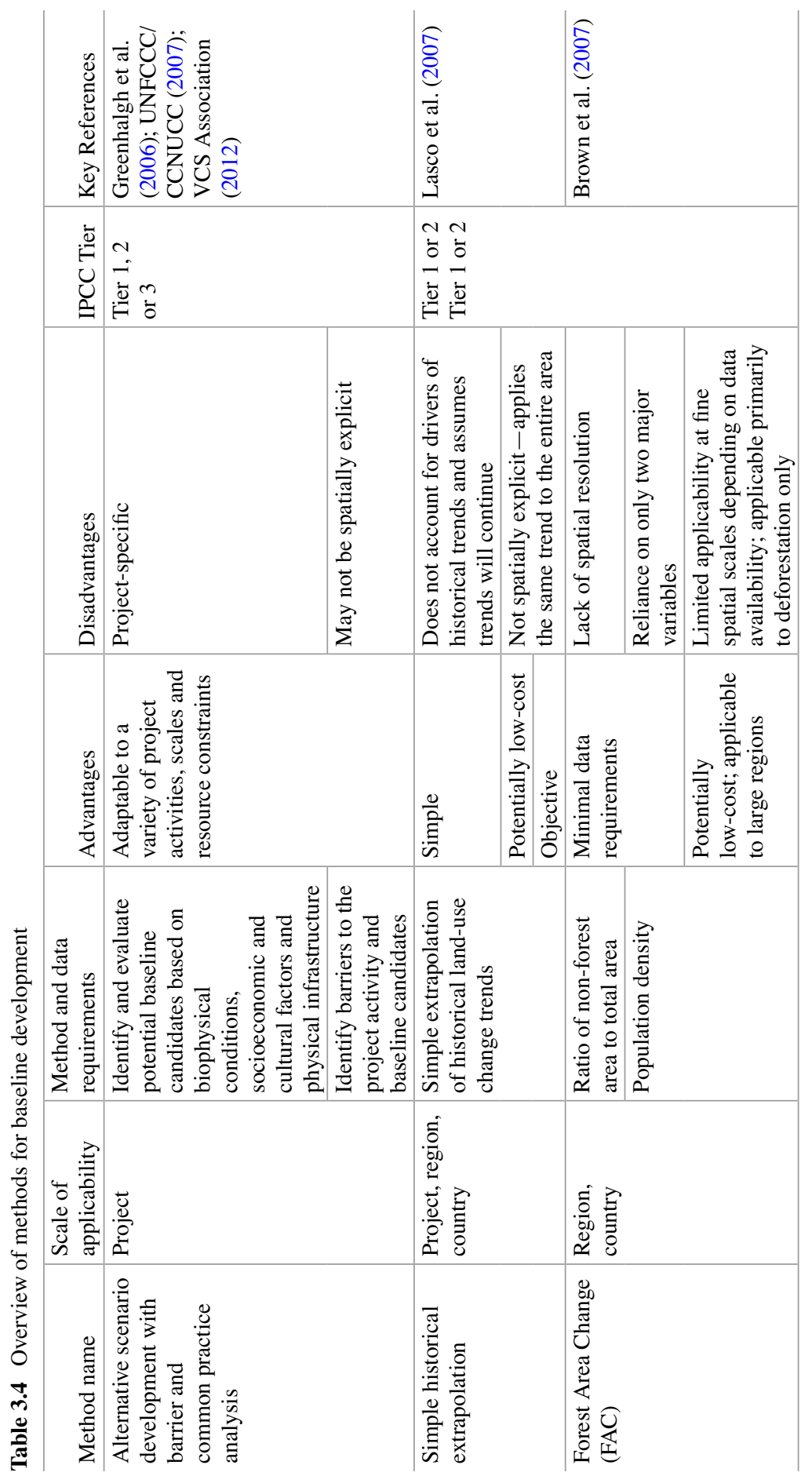




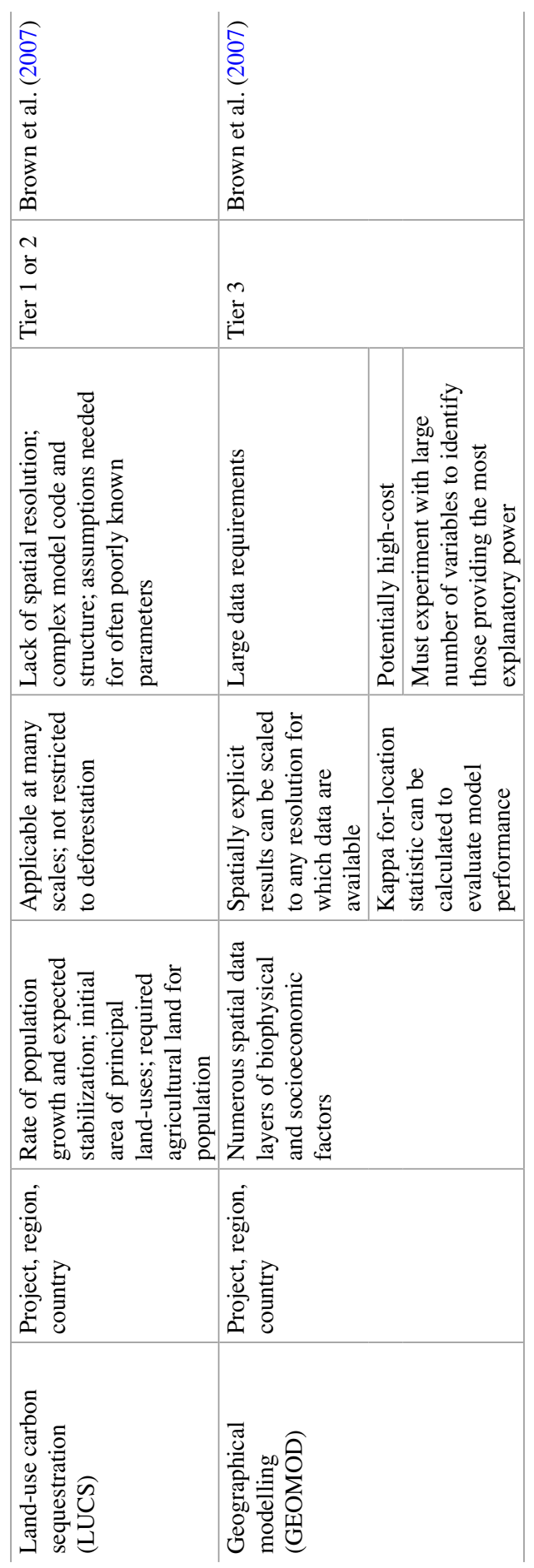


trends may not continue into the future if certain thresholds have been reached or land-use determinants such as road networks have changed (Chomitz and Gray 1996). Incorporating such factors into models can improve trend prediction and many different models exist to analyze the influence of drivers and set baselines (e.g., Brown et al. 2007). Reporting should describe the model and drivers in detail and the chosen model should be transparent, include empirical calibration and validation processes and generate uncertainty estimates (Greenhalgh et al. 2006).

To qualify for carbon crediting under the VCS, Clean Development Mechanism (CDM), REDD+ or other mechanisms, the baseline must generally be justified using investment, barrier and/or common practice analysis (Greenhalgh et al. 2006; Tomich et al. 2001; VCS Association 2012). In other words, barriers to the LULC changes sought by project activities or policies must be identified to show that insufficient incentives exist to achieve the desired LULC changes without intervention. Ideally multiple scenarios will be developed and evaluated to determine which is the most credible and conservative baseline choice. Several temporal considerations also exist related to both the historical period used to generate a baseline scenario and the period for which the baseline is projected forward. Historical data should be as relevant as possible to the projected period and major events (e.g., hurricanes, fires) and policy changes (e.g., protected area designations) should be considered when acquiring historical data. A narrative approach exploring the story behind historical LULC dynamics can further reveal relationships between observed changes and the forces driving them (Lambin et al. 2003). The validity period for the baseline (i.e., for how many years the baseline is considered valid and accurate) should also be taken into account. Experience from other projects suggests that an adjustable baseline approach is preferable. A common approach is to set a fixed baseline for the first 10 years, at which point it is evaluated and adjusted as needed (Brown et al. 2007; Sathaye and Andrasko 2007; VCS Association 2014).

\subsubsection{Reference Regions}

An alternative to developing a baseline scenario for the project area is to monitor a separate reference region, a common approach among Voluntary Carbon Standard (VCS) methodologies (e.g., VCS Association 2010 and others). The reference region should be sufficiently similar to the project area to conclude that the trajectory of LULC change observed in the reference region would also have occurred within the project area in the absence of project activities. While exact requirements for identification of a reference region vary, in general the reference region must be significantly larger than and demonstrably similar to the inventory area. In order to demonstrate similarity, key variables must be compared which may include landscape features (e.g., slope, elevation, LULC distribution), ecological variables (e.g., rainfall, temperature, soil type) and socioeconomic conditions (e.g., population, land tenure status, policies, and regulations) (see VCS Association 2010). Transparent comparison procedures must be developed to set comparative thresholds for the reference region (e.g., average slope of the reference region shall be within $10 \%$ of the average slope of the inventory area). 
Monitoring a reference region may be a cost-effective option for small projects that can easily identify an area similar to the project area. However larger projects, or projects working in a unique biophysical or sociopolitical environment, may find it difficult to locate an appropriate reference region, or may find it cost-prohibitive to monitor one.

\subsection{Calculating Carbon Stock Changes}

In order to estimate GHG emissions and removals, carbon stock densities must be quantified for each LULC category subclass and/or stratum. Carbon stock densities may come from default values, national datasets, scientific studies or field sampling and are generally given as tons of carbon per hectare $\left(\mathrm{Mg} \mathrm{Cha}^{-1}\right)$ for individual or combined carbon pools (Table 3.5).

\subsubsection{Key Carbon Pools}

The IPCC Guidelines (2006) define five carbon pools: living aboveground biomass, living belowground biomass, deadwood, litter and soil organic matter (SOM). In the case that data are not available for all carbon pools, key pools can be identified based on their relative expected contribution to total carbon stock changes caused by possible LULC transitions. Thresholds are developed to delimit the minimum contribution of total emissions from a pool to be defined as "key." For example, a threshold could be created stating that only pools representing more than $10 \%$ of total carbon stocks are considered key. Therefore it is possible that some pools will be key for certain LULC classes but not for others. Identifying key pools can help target monitoring and modelling efforts to minimize uncertainty and is required under IPCC reporting.

\subsubsection{Initial Carbon Stock Estimates}

Calculation of initial carbon stocks can be done in several ways ranging from the use of simple arithmetic to running complex models. The simplest method is to assign a single carbon stock density value (or range of values) to each LULC category and multiply this value by the total area of each category. This method can be used with activity data associated with any of the three Approaches. It is relatively straightforward and potentially low-cost, but may introduce high levels of uncertainty as it assumes that there is no variability of carbon stocks within LULC categories.

Uncertainty can be reduced by taking into account additional drivers of carbon stocks beyond just LULC categories. This can be done through stratification (Sect. 3.2.3) and/or modelling. Modelling approaches require data on carbon stocks and rates of change, which can be obtained from default emission factors, scientific research, or field measurements. Additional biophysical (e.g., slope, rainfall, soil type) and socioeconomic (e.g., population) datasets may also be needed. A variety 
Table 3.5 Summary of activities for calculating carbon stock changes from LULC change at various uncertainty levels

\begin{tabular}{|c|c|c|c|c|}
\hline Activity & $\begin{array}{l}\text { Higher } \\
\text { uncertainty }\end{array}$ & $\begin{array}{l}\text { Mid-range } \\
\text { uncertainty }\end{array}$ & Lower uncertainty & Key references \\
\hline \multirow[t]{2}{*}{$\begin{array}{l}\text { Define key } \\
\text { carbon } \\
\text { pools }\end{array}$} & $\begin{array}{l}\text { Key pools } \\
\text { identified using } \\
\text { international or } \\
\text { default data; }\end{array}$ & $\begin{array}{l}\text { Key pools } \\
\text { identified using } \\
\text { region-specific } \\
\text { or field-based } \\
\text { data }\end{array}$ & $\begin{array}{l}\text { Key pools identified for } \\
\text { each LULC class using } \\
\text { field sampling, or }\end{array}$ & \multirow[t]{2}{*}{$\begin{array}{l}\text { GOFC-GOLD } \\
\text { (2014); IPCC } \\
\text { (2006, Volume } \\
\text { 4, Chap. 2) }\end{array}$} \\
\hline & $\begin{array}{l}\text { Same key pools } \\
\text { applied to all } \\
\text { LULC classes }\end{array}$ & $\begin{array}{l}\text { Key pools } \\
\text { defined } \\
\text { separately for at } \\
\text { least broad } \\
\text { LULC categories }\end{array}$ & $\begin{array}{l}\text { Data available for all } \\
\text { carbon pools }\end{array}$ & \\
\hline \multirow[t]{2}{*}{$\begin{array}{l}\text { Initial } \\
\text { carbon } \\
\text { stock } \\
\text { estimates }\end{array}$} & \multirow[t]{2}{*}{$\begin{array}{l}\text { Single carbon } \\
\text { stock density } \\
\text { applied to each } \\
\text { LULC class } \\
\text { based on global } \\
\text { or regional } \\
\text { default data }\end{array}$} & \multirow{2}{*}{$\begin{array}{l}\text { Carbon stocks } \\
\text { stratified by } \\
\text { subclasses or } \\
\text { additional strata } \\
\text { and derived from } \\
\text { country-specific } \\
\text { data and/or field } \\
\text { sampling for key } \\
\text { carbon pools }\end{array}$} & $\begin{array}{l}\text { Spatially explicit } \\
\text { stratification and } \\
\text { modelling of carbon } \\
\text { stocks using empirically } \\
\text { derived drivers of } \\
\text { observed carbon stock } \\
\text { variability; or }\end{array}$ & \multirow[t]{2}{*}{$\begin{array}{l}\text { Goetz et al. } \\
(2009) ; \\
\text { GOFC-GOLD } \\
\text { (2014); } \\
\text { Greenhalgh } \\
\text { et al. (2006); } \\
\text { IPCC (2006) }\end{array}$} \\
\hline & & & $\begin{array}{l}\text { Direct carbon stock } \\
\text { monitoring approaches } \\
\text { (e.g., using LiDAR, } \\
\text { RADAR, optical sensors) }\end{array}$ & \\
\hline \multirow[t]{2}{*}{$\begin{array}{l}\text { Monitoring } \\
\text { carbon } \\
\text { stock } \\
\text { changes }\end{array}$} & \multirow{2}{*}{$\begin{array}{l}\text { Process-based } \\
\text { method using } \\
\text { default } \\
\text { emissions } \\
\text { factors assigned } \\
\text { to LULC classes } \\
\text { and change } \\
\text { processes (e.g., } \\
\text { deforestation) }\end{array}$} & \multirow[t]{2}{*}{$\begin{array}{l}\text { Process-based } \\
\text { method using } \\
\text { emission factors } \\
\text { derived from } \\
\text { country- or } \\
\text { region-specific } \\
\text { data }\end{array}$} & $\begin{array}{l}\text { Process-based method } \\
\text { using emission factors } \\
\text { derived from field } \\
\text { sampling within the } \\
\text { project area or research } \\
\text { activities in highly } \\
\text { similar areas }\end{array}$ & \multirow[t]{2}{*}{$\begin{array}{l}\text { Greenhalgh } \\
\text { et al. (2006); } \\
\text { Houghton } \\
\text { et al. (2012); } \\
\text { IPCC (2006, } \\
\text { Volume 4, } \\
\text { Chap. 2) }\end{array}$} \\
\hline & & & $\begin{array}{l}\text { Stock-based methods } \\
\text { using multitemporal } \\
\text { carbon stock inventories } \\
\text { for key pools }\end{array}$ & \\
\hline
\end{tabular}

of models such as PROCOMAP, $\mathrm{CO}_{2}$ FIX, CENTURY, ROTH, and others exist with a range of complexity and data requirements. (See Ravindranath and Ostwald 2008 for a good comparison of several models.)

\subsubsection{Monitoring Carbon Stock Changes}

Carbon stock changes are estimated using one of two general methods: one processbased and the other stock-based. The process-based method estimates the net additions to, or removals from, each carbon pool based on processes and activities that result in carbon stock changes, such as tree harvesting, fires, etc. The stock-based method estimates emissions and removals by measuring carbon stocks in key pools at two or more points in time. 


\section{Process-Based Method}

The process-based method (sometimes called the gain-loss, IPCC default or emission factor method) estimates gains or losses of carbon in each pool by simulating changes resulting from disturbance or recovery (Houghton et al. 2012). Changes in LULC drive process-based models, and carbon stocks are re-allocated based on observed or modelled LULC change. Gains are a result of carbon accumulation from the atmosphere (e.g., in tree biomass) or transfers from another pool (e.g., from biomass to SOC via decomposition). Losses are attributed to transfers to another pool or emissions to the atmosphere as $\mathrm{CO}_{2}$ or other GHGs (IPCC 2006, Volume 4, Chap. 2). Additional emission factors can be developed for emitting activities that do not necessarily affect the five carbon pools identified by the IPCC. These include, for example, direct emissions from livestock, farm equipment or the production of nonfood products. Models and emission factors used in process-based methods can vary in complexity and potentially meet any Tier requirements. IPCC default factors can be used to achieve Tier 1 reporting requirements whereas country-specific or locally derived research data combined with more complex modelling approaches are required to meet Tier 2 and 3 requirements.

\section{Stock-Based Method}

The stock-based method (also called the bookkeeping, stock-difference, or stockchange method) combines ground-based and/or remotely sensed data of measured carbon stocks with data on changes in the total land area of each LULC class between two or more points in time. For stock-based methods, carbon stock changes are measured independently of LULC change and are then multiplied by the total area of each LULC class and stratum. Process-based methods model carbon stock changes based on LULC changes. Depending on the spatial resolution of data, conversions might be required to arrive at a carbon density $\left(\mathrm{Mg} \mathrm{C} \mathrm{ha}^{-1}\right)$ that is then combined with activity data to estimate total emissions/removals. Typically, country-specific information is required for use with the stock-based method and resource requirements for data collection may be greater than process-based methods unless appropriate datasets already exist. Stock-based methods often meet at least Tier 2 requirements, provided activity data were generated according to Approach 2 or 3.

\subsection{Assessing Accuracy and Calculating Uncertainty}

In order to qualify for carbon crediting under mechanisms such as VCS, CDM, and REDD+, final reporting of GHG emissions/removals associated with LULC change must include uncertainty estimates (Maniatis and Mollicone 2010). Uncertainty should be reported as the range within which the mean value lies for a given probability (e.g., a $95 \%$ confidence interval) or the percent uncertainty of the mean value, each of which can be calculated from the other (IPCC 2003). Errors will be 
introduced at every level of data collection. Analysis and assessment of accuracy and uncertainty should be carried out for each step. Not only is this important for reporting purposes, it can provide valuable information to project managers to determine which steps contain the greatest sources of uncertainty, thereby encouraging cost-effective monitoring (e.g., Smits et al. 1999).

In this chapter we focus on estimating uncertainty associated with the collection of activity data, detection of LULC changes, and linking of emission factors and/or carbon stocks. Methods for assessing uncertainty related to the production of emission factors and measurement of carbon stocks (e.g., calculating soil carbon in a forest) are discussed elsewhere.

\subsubsection{LULC Classification Accuracy Assessment}

When remote sensing data are used to develop wall-to-wall LULC maps, two types of error exist: errors of inclusion (commission errors) and errors of exclusion (omission errors). Accuracy should be assessed using a statistically valid method, the most common method being statistical sampling of independent higher-quality validation sample units (e.g., pixels, polygons, sites) for comparison against classified sample units (Congalton 1991) (Table 3.6). These validation samples can be taken from field observations, additional higher-resolution remote sensing imagery, or can be visually identified from within the original image provided they are independent from those used during training. As with the selection of training data, validation sampling should be done in a statistically sound and transparent manner. Stratified or proportional sampling techniques may be desirable to improve accuracy and reduce costs. When using field-based sampling to analyze current imagery, validation data should be collected as close to the time of image acquisition as possible, ideally at the same time as training data. Including farmers or other community members in the data collection process can be an effective way to estimate past LULC for classification and validation of historical imagery, while at the same time empowering stakeholders and addressing conservation issues (e.g., Sydenstricker-Neto et al. 2004).

The accuracy of classified sample units compared against "real-world" validation sample units can be presented in an error matrix, also called a confusion matrix. This helps visualize errors, identify relationships between errors and LULC categories, and calculate indices of accuracy and variation (Congalton 1991). Classification accuracy refers to the percentage of sample units correctly classified and can be calculated as commission and omission errors for each LULC class as well as an overall accuracy for all classes (Table 3.7). These classification accuracies can then be used as an uncertainty estimate to discount carbon credits associated with LULC change. For example, to maintain conservativeness of carbon credit estimates the VCS Association VM0006 (2010) uses the smallest accuracy of all maps as a discount factor for carbon credits. In the hypothetical example from Table 3.7, this would result in carbon credits being discounted by $25 \%$ (multiplied by a discount factor of 0.75 ). Representing accuracy using an error matrix also provides an opportunity to assess which LULC categories are most often confused. For example, cropland in smallholder landscapes 
Table 3.6 Summary of activities for assessing accuracy and calculating uncertainty at various uncertainty levels

\begin{tabular}{|c|c|c|c|c|}
\hline Activity & $\begin{array}{l}\text { Higher } \\
\text { uncertainty }\end{array}$ & $\begin{array}{l}\text { Mid-range } \\
\text { uncertainty }\end{array}$ & Lower uncertainty & Key references \\
\hline \multirow[t]{2}{*}{$\begin{array}{l}\text { LULC area } \\
\text { estimates } \\
\text { and change } \\
\text { detection }\end{array}$} & \multirow[t]{2}{*}{$\begin{array}{l}\text { Assessment of } \\
\text { data collection } \\
\text { procedures to } \\
\text { ensure data } \\
\text { quality, but } \\
\text { without the } \\
\text { use of } \\
\text { methods to } \\
\text { quantify } \\
\text { uncertainty }\end{array}$} & \multirow{2}{*}{$\begin{array}{l}\text { Assessment of data } \\
\text { quality through } \\
\text { systematic analysis } \\
\text { of data collection } \\
\text { procedures; or error } \\
\text { matrix with Kappa } \\
\text { coefficient based on } \\
\text { validation points } \\
\text { from limited field } \\
\text { ground-truthing or } \\
\text { marginally } \\
\text { higher-quality } \\
\text { imagery }\end{array}$} & $\begin{array}{l}\text { Confusion matrix } \\
\text { with Kappa } \\
\text { coefficient based } \\
\text { on validation } \\
\text { points from } \\
\text { ground-truthing } \\
\text { in the field or } \\
\text { higher-quality } \\
\text { imagery }\end{array}$ & \multirow[t]{2}{*}{$\begin{array}{l}\text { Congalton (1991); } \\
\text { IPCC (2006, } \\
\text { Volume 4, Chap. 3) }\end{array}$} \\
\hline & & & $\begin{array}{l}\text { Calculation of } \\
\text { confidence } \\
\text { intervals for } \\
\text { LULC category } \\
\text { areas and changes } \\
\text { in area }\end{array}$ & \\
\hline
\end{tabular}

Carbon stock Varies by carbon pool; See Chaps. 6 and 7 for more information estimates

\begin{tabular}{|c|c|c|c|c|}
\hline $\begin{array}{l}\text { Combining } \\
\text { uncertainty } \\
\text { estimates }\end{array}$ & $\begin{array}{l}\text { Simple error } \\
\text { propagation }\end{array}$ & $\begin{array}{l}\text { Error propagation } \\
\text { using more complex } \\
\text { equations and } \\
\text { controlling for } \\
\text { correlation of input } \\
\text { data }\end{array}$ & $\begin{array}{l}\text { Monte Carlo } \\
\text { simulations or } \\
\text { other } \\
\text { bootstrapping } \\
\text { techniques }\end{array}$ & $\begin{array}{l}\text { GOFC-GOLD } \\
\text { (2014); IPCC } \\
\text { (2003); } \\
\text { Ravindranath and } \\
\text { Ostwald (2008); } \\
\text { Saatchi et al. (2007) }\end{array}$ \\
\hline
\end{tabular}

Table 3.7 Hypothetical error matrix showing the number of pixels mapped and validated (groundtruthed) by LULC class. Values in bold highlight the number of correctly mapped pixels and the row and column totals, which are used to calculate producer's and user's accuracy

\begin{tabular}{|c|c|c|c|c|c|c|c|}
\hline \multirow{2}{*}{$\begin{array}{l}\text { Mapped } \\
\text { classes }\end{array}$} & \multicolumn{7}{|c|}{ Ground truth classes } \\
\hline & Forest & Cropland & Grassland & Wetland & Settlements & Other land & Total \\
\hline Forest & 900 & 50 & 50 & 0 & 0 & 0 & 1000 \\
\hline Cropland & 50 & 750 & 150 & 30 & 20 & 0 & 1000 \\
\hline Grassland & 30 & 60 & 810 & 70 & 20 & 10 & 1000 \\
\hline Wetland & 30 & 30 & 30 & 390 & 0 & 20 & 500 \\
\hline Settlements & 0 & 20 & 20 & 10 & 420 & 30 & 500 \\
\hline Other land & 0 & 20 & 0 & 0 & 30 & 450 & 500 \\
\hline \multirow[t]{2}{*}{ Total } & 1010 & 930 & 1060 & 500 & 490 & 510 & 4500 \\
\hline & \multicolumn{3}{|c|}{$\begin{array}{l}\text { Producer's accuracy } \\
\text { (omission error) }\end{array}$} & \multicolumn{2}{|c|}{$\begin{array}{l}\text { User's accuracy } \\
\text { (commission error) }\end{array}$} & & \\
\hline Forest & \multicolumn{2}{|c|}{$900 / 1010$} & $89 \%$ & $900 / 1000$ & \multicolumn{3}{|l|}{$90 \%$} \\
\hline Cropland & \multicolumn{2}{|c|}{$750 / 930$} & $81 \%$ & $750 / 1000$ & $75 \%$ & \multicolumn{2}{|c|}{ Overall accuracy } \\
\hline Grassland & \multicolumn{2}{|c|}{$810 / 1060$} & $76 \%$ & $810 / 1000$ & $81 \%$ & $3720 / 4500$ & $83 \%$ \\
\hline Wetland & $390 /$ & & $\%$ & $/ 500$ & $78 \%$ & & \\
\hline Settlements & $420 /$ & & $\%$ & $/ 500$ & $84 \%$ & & \\
\hline Other land & $450 /$ & & & $/ 500$ & $90 \%$ & & \\
\hline
\end{tabular}


is often misclassified due to small farm sizes and its resemblance to bare soil (due to minimal reflectance from young crops) or secondary forests (due to intercropping with tree species commonly found in secondary forests) (e.g., Sydenstricker-Neto et al. 2004). Other accuracy indicators include the kappa coefficient or KHAT statistic, root mean squared error (RMSE), adjusted $R^{2}$, Spearman's rank coefficient and others (Congalton 1991; Jain et al. 2013; Lesschen et al. 2005; Smits et al. 1999).

\subsubsection{LULC Change Detection Accuracy Assessment}

The accuracy of LULC change detection can be assessed using methods similar to those used to validate single scene LULC classification, but additional considerations exist. When making post-classification comparisons using two independently classified images, the accuracy of each individual classification should be assessed in addition to the accuracy of the change image. It is usually easier to identify errors of commission in change products because often only a small proportion of the land area will have experienced change, and often within a limited geographic area (GOFC-GOLD 2014). Unique sampling methodologies may therefore prove more cost-effective to validate the relatively rare event of changes in LULC within an image (Lowell 2001). A transition error matrix can be used to report the accuracy with which transitions between LULC categories are detected. This allows for assessment of uncertainty for each transition (e.g., forest to cropland, forest to grassland) and for partitioning of uncertainty attributable to the change detection process versus classification (van Oort 2007).

\subsubsection{Uncertainty Associated with Estimating Carbon Stocks}

Uncertainty estimates should be developed for key carbon pools within each LULC category. Uncertainty of carbon stocks using the stock-based method will be related to sampling. The process-based method will contain uncertainty estimates derived from scientific literature, model accuracy or other sources. Factors such as the scale of aggregation, stratification variables, and the spatial or temporal considerations discussed above can all influence the uncertainty associated with integrating carbon stocks and activity data.

\subsubsection{Combining Uncertainty Values and Reporting Total Uncertainty}

Combining uncertainty estimates for activity data, LULC change detection and emissions factors or carbon stocks can be done several ways, ranging from simple error propagation calculations (Tier 1) to more complex Monte Carlo simulations, also called bootstrapping or bagging (Tiers 2 and 3). Several approaches exist for 
calculating error propagation. For example, different equations are recommended if input data are correlated (e.g., the same activity data or emission factors were used to calculate multiple input factors that are to be summed) or if individual uncertainty values are high (e.g., greater than $30 \%$ ) (GOFC-GOLD 2014; IPCC 2003). Monte Carlo simulations select random values within probability distribution functions (PDF) developed for activity data and associated carbon stock estimates to calculate corresponding changes in carbon stocks. The PDFs represent the variability of the input variables and the simulation is undertaken many times to produce a mean carbon stock-change value and range of uncertainty (see IPCC 2003 and citations within for more detailed information on running Monte Carlo simulations). Simulation results can be combined with classification accuracies to compute uncertainties for each pixel. This allows exploration of the variation of accuracy by LULC class or stratum, and where to target future measurements to achieve the greatest reductions in overall uncertainty (Saatchi et al. 2007). Generally speaking, Monte Carlo simulations require greater resources than error propagation equations, but both methods require quantitative uncertainty estimates for activity data, LULC changes, and carbon stocks.

\subsection{Challenges, Limitations, and Emerging Technologies}

Monitoring LULC change and associated GHG emissions/reductions in a costeffective manner remains a challenge in heterogeneous landscapes such as those dominated by smallholder agriculture. Monitoring change in management within LULC categories can be even more challenging, yet management is often a key component of smallholder carbon projects. Technologies are emerging to directly monitor carbon stocks (namely aboveground biomass), which could overcome some of these challenges. For example LiDAR shows promise for accurate direct estimation of vegetation structure, aboveground biomass, and carbon stocks (Goetz and Dubayah 2011; Goetz et al. 2009). While direct measurement methods are generally still in the research phase and may be cost-prohibitive for most projects, they may prove especially useful for smallholder settings as they can improve accuracy by removing the error associated with misclassification of LULC, a potentially large source of uncertainty in heterogeneous landscapes. In the end, it is difficult to recommend a single methodological approach to monitoring LULC in smallholder landscapes as optimal methods will depend on the project area, size, available resources, time period, interventions, and other factors. An overall summary of the general methods discussed in each section of this chapter is presented in Table 3.8. Time should be taken to assess these methods and their associated trade-offs, read the relevant key references and stay abreast of emerging remote sensing options to identify the most appropriate methodology for specific project conditions. 


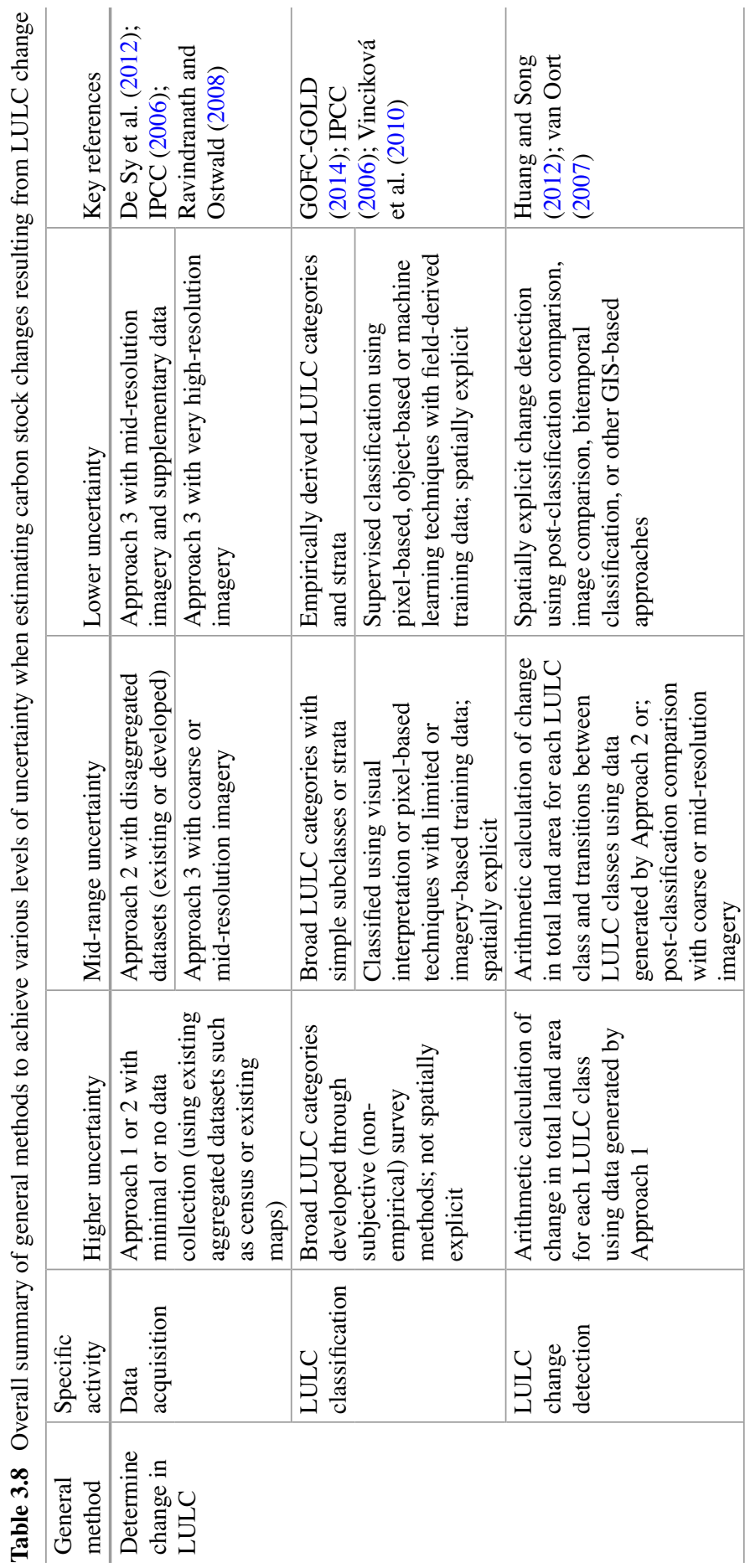


3 Determining Greenhouse Gas Emissions and Removals Associated with Land-Use...

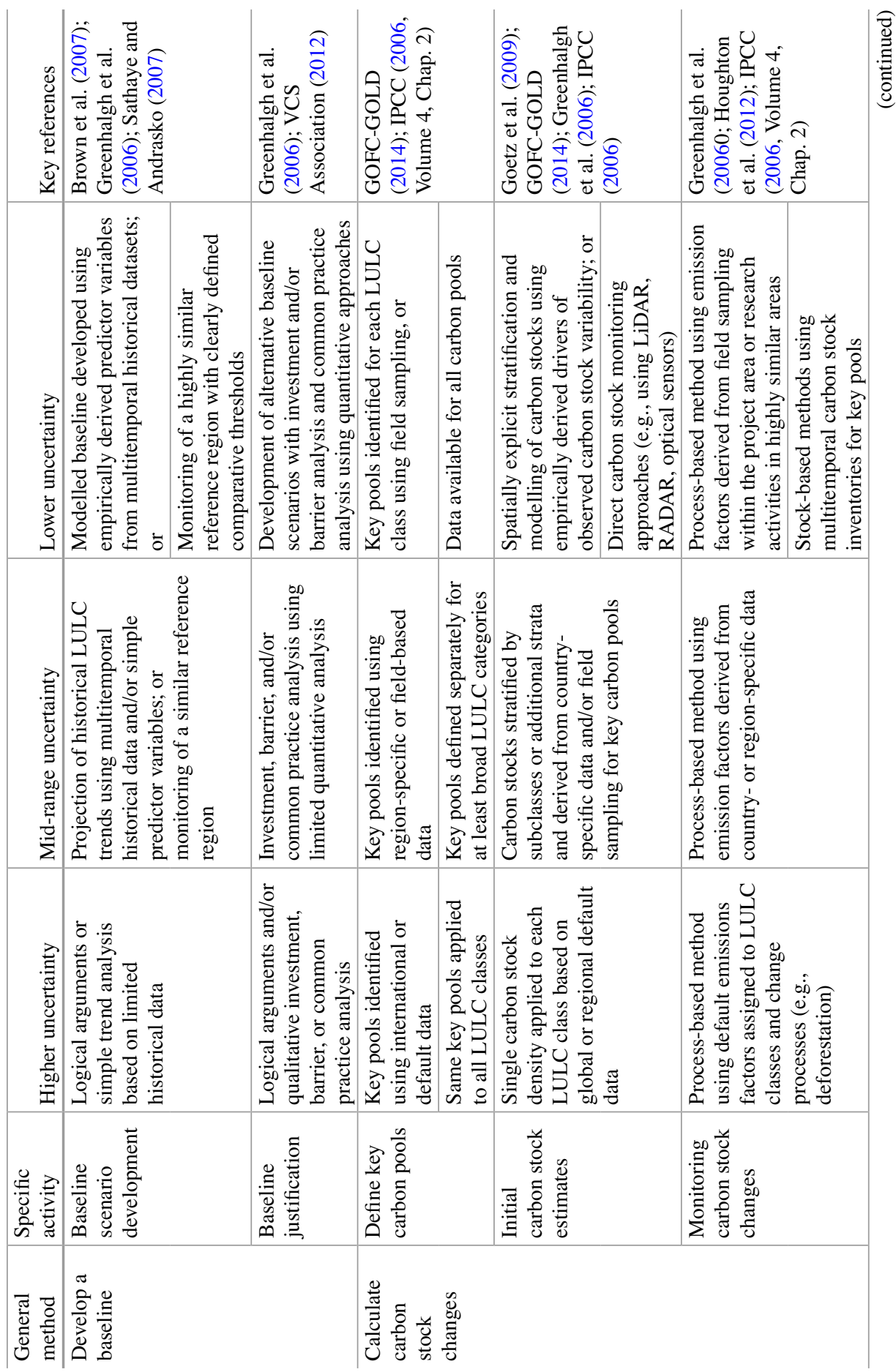




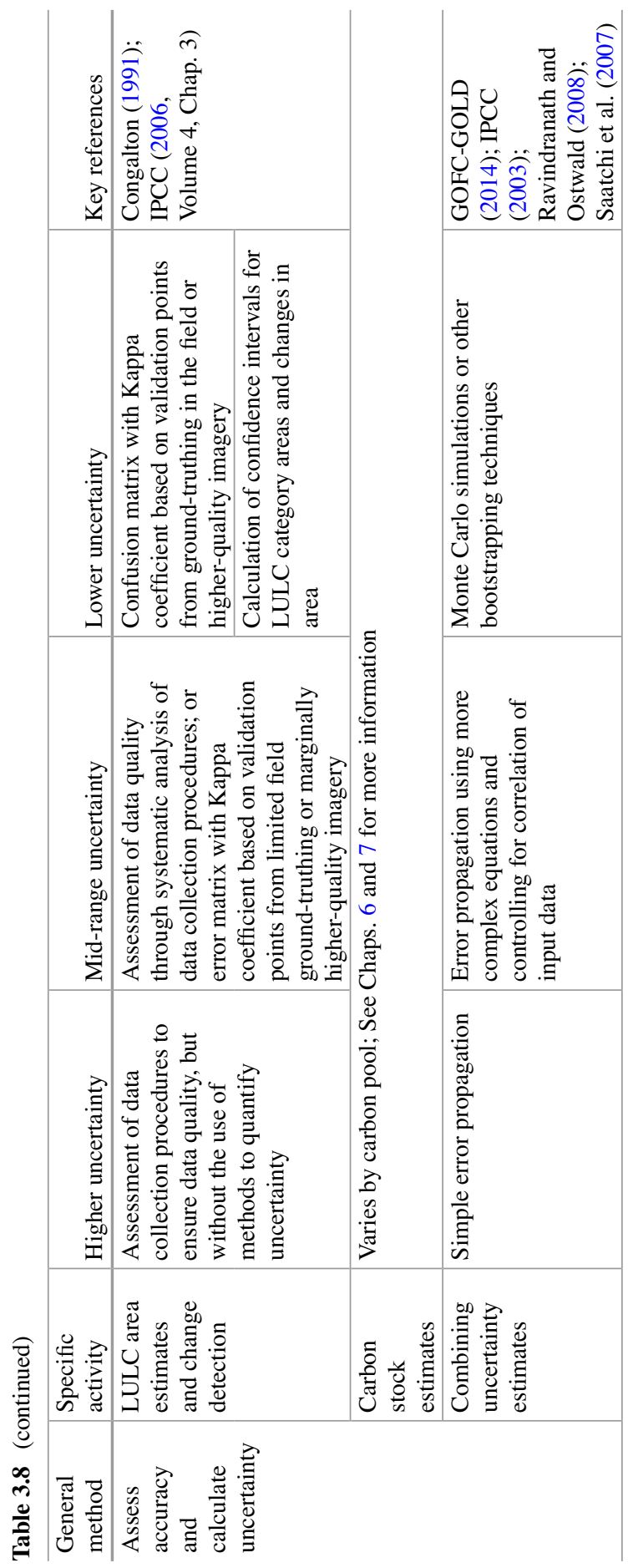


Open Access This chapter is distributed under the terms of the Creative Commons Attribution 4.0 International License (http://creativecommons.org/licenses/by/4.0/), which permits use, duplication, adaptation, distribution and reproduction in any medium or format, as long as you give appropriate credit to the original author(s) and the source, a link is provided to the Creative Commons license and any changes made are indicated.

The images or other third party material in this chapter are included in the work's Creative Commons license, unless indicated otherwise in the credit line; if such material is not included in the work's Creative Commons license and the respective action is not permitted by statutory regulation, users will need to obtain permission from the license holder to duplicate, adapt or reproduce the material.

\section{References}

Achard F, Eva HD, Stibig H-J, Mayaux P, Gallego J, Richards T, Malingreau J-P (2002) Determination of deforestation rates of the world's humid tropical forests. Science 297:9991002. doi:10.1126/science. 1070656

Asner GP, Powell GVN, Mascaro J, Knapp DE, Clark JK, Jacobson J, Kennedy-Bowdoin T, Balaji A, Paez-Acosta G, Victoria E, Secada L, Valqui M, Hughes RF (2010) High-resolution forest carbon stocks and emissions in the Amazon. Proc Natl Acad Sci U S A 107:16738-16742. doi:10.1073/pnas.1004875107

Aumtong S, Magid J, Bruun S, de Neergaard A (2009) Relating soil carbon fractions to land use in sloping uplands in northern Thailand. Agric Ecosyst Environ 131:229-239. doi:10.1016/j. agee.2009.01.013

Brown S, Hall M, Andrasko K, Ruiz F, Marzoli W, Guerrero G, Masera O, Dushku A, DeJong B, Cornell J (2007) Baselines for land-use change in the tropics: application to avoided deforestation projects. Mitig Adapt Strateg Glob Chang 12:1001-1026. doi:10.1007/s11027-006-9062-5

Bruun TB, Neergaard A, Lawrence D, Ziegler AD (2009) Environmental consequences of the demise in swidden cultivation in Southeast Asia: carbon storage and soil quality. Hum Ecol 37:375-388. doi:10.1007/s10745-009-9257-y

Castillejo-González IL, López-Granados F, García-Ferrer A, Peña-Barragán JM, Jurado-Expósito M, de la Orden MS, González-Audicana M (2009) Object- and pixel-based analysis for mapping crops and their agro-environmental associated measures using QuickBird imagery. Comput Electron Agric 68:207-215. doi:10.1016/j.compag.2009.06.004

Chomitz KM, Gray D (1996) Roads, land use, and deforestation: a spatial model applied to Belize. World Bank Econ Rev 10:487-512. doi:10.1093/wber/10.3.487

Congalton RG (1991) A review of assessing the accuracy of classifications of remotely sensed data. Remote Sens Environ 37:35-46. doi:10.1016/0034-4257(91)90048-B

De Sy V, Herold M, Achard F, Asner GP, Held A, Kellndorfer J, Verbesselt J (2012) Synergies of multiple remote sensing data sources for REDD+ monitoring. Curr Opin Environ Sustain 4:696-706. doi:10.1016/j.cosust.2012.09.013

DeFries R, Achard F, Brown S, Herold M, Murdiyarso D, Schlamadinger B, de Souza C (2007) Earth observations for estimating greenhouse gas emissions from deforestation in developing countries. Environ Sci Pol 10:385-394. doi:10.1016/j.envsci.2007.01.010

Eaton JM, Lawrence D (2009) Loss of carbon sequestration potential after several decades of shifting cultivation in the Southern Yucatán. For Ecol Manage 258:949-958. doi:10.1016/j. foreco.2008.10.019

Ellis EC (2004) Long-term ecological changes in the densely populated rural landscapes of China. In: DeFries RS, Asner GP, Houghton RA (eds) Ecosystems and land use change. American Geophysical Union, Washington, DC, pp 303-320. doi:10.1029/153GM23

Ellis EC, Ramankutty N (2008) Putting people in the map: anthropogenic biomes of the world. Front Ecol Environ 6:439-447. doi:10.1890/070062 
Ellis EC, Li RG, Yang LZ, Cheng X (2000) Long-term change in village-scale ecosystems in China using landscape and statistical methods. Ecol Appl 10:1057-1073. doi:10.2307/2641017

Foody GM (1996) Approaches for the production and evaluation of fuzzy land cover classifications from remotely-sensed data. Int J Remote Sens 17:1317-1340. doi:10.1080/01431169608948706

Goetz S, Dubayah R (2011) Advances in remote sensing technology and implications for measuring and monitoring forest carbon stocks and change. Carbon Manag 2:231-244. doi:10.4155/ cmt.11.18

Goetz SJ, Baccini A, Laporte N, Johns T, Walker W, Kellndorfer J, Houghton R, Sun M (2009) Mapping and monitoring carbon stocks with satellite observations: a comparison of methods. Carbon Balance Manag 4:1-7. doi:10.1186/1750-0680-4-2

GOFC-GOLD (2014) A sourcebook of methods and procedures for monitoring and reporting anthropogenic greenhouse gas emissions and removals associated with deforestation, gains and losses of carbon stocks in forests remaining forests, and forestation. GOFC-GOLD Report version COP20-1, GOFC-GOLD Land Cover Project Office, Wageningen University, The Netherlands

Greenhalgh S, Daviet F, Weninger E (2006) The land use, land-use change, and forestry guidance for GHG project accounting. World Resources Institute, Washington, DC

Hansen MC, Potapov PV, Moore R, Hancher M, Turubanova SA, Tyukavina A, Thau D, Stehman SV, Goetz SJ, Loveland TR, Kommareddy A, Egorov A, Chini L, Justice CO, Townshend JRG (2013) High-resolution global maps of 21st-century forest cover change. Science 342(6160):850-853. doi:10.1126/science.1244693

Houghton R, House JI, Pongratz J, van der Werf GR, DeFries RS, Hansen MC, Le Quéré C, Ramankutty N (2012) Carbon emissions from land use and land-cover change. Biogeosciences 9:5125-5142. doi:10.5194/bg-9-5125-2012

Huang C, Song K (2012) Forest-cover change detection using support vector machines. In: Giri CP (ed) Remote sensing of land use and land cover, remote sensing applications series. CRC Press, Boca Raton, pp 191-206. doi:10.1201/b11964-16

Hughes R, Kauffman J, Jaramillo V (1999) Biomass, carbon, and nutrient dynamics of secondary forests in a humid tropical region of Mexico. Ecology 80:1892-1907

IPCC (2003) Good practice guidance for land use, land-use change and forestry. Institute for Global Environmental Strategies (IGES), Kanagawa, Japan

IPCC (2006) IPCC guidelines for national greenhouse gas inventories, prepared by the National Greenhouse Gas Inventories Programme. IGES, Geneva

IPCC (n.d.) Emissions Factor Data Base (EFDB). http://www.ipcc-nggip.iges.or.jp/EFDB/main. php. Accessed 14 March 2015

Jain M, Mondal P, DeFries RS, Small C, Galford GL (2013) Mapping cropping intensity of smallholder farms: a comparison of methods using multiple sensors. Remote Sens Environ 134:210-223. doi:10.1016/j.rse.2013.02.029

Jiao J-G, Yang L-Z, Wu J-X, Wang H-Q, Li H-X, Ellis EC (2010) Land use and soil organic carbon in China's village landscapes. Pedosphere 20:1-14. doi:10.1016/S10020160(09)60277-0

Lambin EF, Geist HJ, Lepers E (2003) Dynamics of land use and land cover change in tropical regions. Annu Rev Environ Resour 28:205-241. doi:10.1146/annurev.energy.28.050302.105459

Lasco RD, Pulhin FB, Sales RF (2007) Analysis of leakage in carbon sequestration projects in forestry: a case study of upper Magat watershed, Philippines. Mitig Adapt Strateg Glob Chang 12:1189-1211. doi:10.1007/s11027-006-9059-0

Lesschen JP, Verburg PH, Staal SJ (2005) Statistical methods for analysing the spatial dimension of changes in land use and farming systems. LUCC Report Series 7. International GeosphereBiosphere Programme (IGBP), Nairobi

Lowell K (2001) An area-based accuracy assessment methodology for digital change maps. Int J Remote Sens 22:3571-3596. doi:10.1080/01431160010031270

Maniatis D, Mollicone D (2010) Options for sampling and stratification for national forest inventories to implement REDD+ under the UNFCCC. Carbon Balance Manag 5:1-14. doi:10.1186/1750-0680-5-9 
Messerli P, Heinimann A, Epprecht M (2009) Finding homogeneity in heterogeneity-a new approach to quantifying landscape mosaics developed for the Lao PDR. Hum Ecol 37:291-304. doi:10.1007/s10745-009-9238-1

Moreno AJP, De Larriva JEM (2012) Comparison between new digital image classification methods and traditional methods for land-cover mapping. In: Giri CP (ed) Remote sensing of land use and land cover. CRC Press, Boca Raton, pp 137-152. doi:10.1201/b11964-13

Palm CA, van Noordwijk M, Woomer P, Alegre JC, Arévalo L, Castilla CE, Cordeiro DG, Hairiah K, Kotto-Same J, Moukam A, Parton WJ, Ricse A, Rodrigues V, Sitompul SM (2005) Carbon losses and sequestration with land use change in the humid tropics. In: Palm CA, Vosti SA, Sanchez PA, Ericksen PJ (eds) Slash-and-burn agriculture: the search for alternatives. Columbia University Press, New York, pp 41-63

Perea A, Meroño J, Aguilera M (2009) Algorithms of expert classification applied in Quickbird satellite images for land use mapping. Chilean J Agric Res 69:400-405

Quintano C, Fernández-Manso A, Shimabukuro YE, Pereira G (2012) Spectral unmixing. Int J Remote Sens 33:5307-5340

Ravindranath N, Ostwald M (2008) Carbon inventory methods: handbook for greenhouse gas inventory, carbon mitigation and roundwood production projects, 29th edn. Springer, The Netherlands

Rindfuss RR, Walsh SJ, Turner BL, Fox J, Mishra V (2004) Developing a science of land change: challenges and methodological issues. Proc Natl Acad Sci U S A 101:13976-13981. doi:10.1073/pnas.0401545101

Roder W, Phengchanh S, Keoboulapha B (1995) Relationships between soil, fallow period, weeds and rice yield in slash-and-burn systems of Laos. Plant Soil 176:27-36

Saatchi SS, Houghton R, Dos Santos Alvalá RC, Soares JV, Yu Y (2007) Distribution of aboveground live biomass in the Amazon basin. Glob Chang Biol 13:816-837. doi:10.1111/j.1365-2486.2007.01323.x

Sathaye J, Andrasko K (2007) Land use change and forestry climate project regional baselines: a review. Mitig Adapt Strateg Glob Chang 12:971-1000. doi:10.1007/s11027-006-9061-6

Schmook B (2010) Shifting maize cultivation and secondary vegetation in the Southern Yucatán: successional forest impacts of temporal intensification. Reg Environ Chang 10:233-246. doi:10.1007/s10113-010-0128-2

Serneels S, Said MY, Lambin EF (2001) Land cover changes around a major east African wildlife reserve: The Mara Ecosystem (Kenya). Int J Remote Sens 22:3397-3420. doi:10.1080/01431160152609236

Smith P, Davies C, Ogle S, Zanchi G, Bellarby J, Bird N, Boddey RM, McNamara NP, Powlson D, Cowie A, Noordwijk M, Davis SC, Richter DDB, Kryzanowski L, Wijk MT, Stuart J, Kirton A, Eggar D, Newton-Cross G, Adhya TK, Braimoh AK (2012) Towards an integrated global framework to assess the impacts of land use and management change on soil carbon: current capability and future vision. Glob Chang Biol 18:2089-2101. doi:10.1111/j.1365-2486.2012.02689.x

Smits PC, Dellepiane SG, Schowengerdt RA (1999) Quality assessment of image classification algorithms for land-cover mapping: a review and a proposal for a cost-based approach. Int J Remote Sens 20:1461-1486

Southworth J, Munroe D, Nagendra H (2004) Land cover change and landscape fragmentationcomparing the utility of continuous and discrete analyses for a western Honduras region. Agric Ecosyst Environ 101:185-205. doi:10.1016/j.agee.2003.09.011

Sydenstricker-Neto J, Parmenter AW, DeGloria S (2004) Participatory reference data collection methods for accuracy assessment of land-cover change maps. In: Lunetta RS, Lyon JG (eds) Remote sensing and GIS accuracy assessment. CRC Press, Boca Raton, pp 75-90. doi:10.1201/9780203497586.ch6

Tomich T, Van Noordwijk M, Budidarsono S, Gillison A, Kusumanto T, Murdiyarso D, Stolle F, Fagi AM (2001) Agricultural intensification, deforestation and the environment: assessing trade-offs in Sumatra, Indonesia. In: Lee DR, Barrett CB (eds) Trade-offs or synergies? Agricultural intensification, economic development, and the environment. CAB International, Wallingford, pp 221-244 
UNFCCC/CCNUCC (2007) A/R methodological tool: combined tool to identify the baseline scenario and demonstrate additionality in A/R CDM project activities (Version 01) (No. EB 35 Report Annex 19) United Nations Framework Convention on Climate Change Clean Development Mechanism. https://cdm.unfccc.int/Reference/tools/index.html. Accessed 14 March 2015

UNFCCC/CCNUCC (2009) A/R methodological tool: calculation of the number of sample plots for measurements within A/R CDM project activities (Version 02) (No. EB 58 Report Annex 15) United Nations Framework Convention on Climate Change Clean Development Mechanism. https://cdm.unfccc.int/Reference/tools/index.html. Accessed 14 March 2015

Van Oort PJ (2007) Interpreting the change detection error matrix. Remote Sens Environ 108:1-8. doi:10.1016/j.rse.2006.10.012

VCS Association (2010) VM0006: methodology for carbon accounting in project activities that reduce emissions from mosaic deforestation and degradation (Version 1.0) Verified Carbon Standard,Washington,DC.http://www.v-c-s.org/methodologies/methodology-carbon-accountingmosaic-and-landscape-scale-redd-projects-v21. Accessed 14 March 2015

VCS Association (2012) VT0001: tool for the demonstration and assessment of additionality in VCS Agriculture, Forestry and Other Land Use (AFOLU) project activities (Version 3.0) Verified Carbon Standard, Washington, DC. http://www.v-c-s.org/methodologies/tooldemonstration-and-assessment-additionality-vcs-agriculture-forestry-and-other. Accessed 14 March 2015

VCS Association (2014) Carbon accounting for grouped mosaic and landscape-scale REDD projects VM0006: methodology for carbon accounting in project activities that reduce emissions from mosaic deforestation and degradation (Version 2.1) Verified Carbon Standard, Washington, DC. http://www.v-c-s.org/methodologies/methodology-carbon-accounting-mosaic-and-landscapescale-redd-projects-v21. Accessed 14 March 2015

Verburg PH, van de Steeg J, Veldkamp A, Willemen L (2009) From land cover change to land function dynamics: a major challenge to improve land characterization. J Environ Manage 90:1327-1335. doi:10.1016/j.jenvman.2008.08.005

Vinciková H, Hais M, Brom J, Procházka J, Pecharová E (2010) Use of remote sensing methods in studying agricultural landscapes - a review. J Landsc Stud 3:53-63 